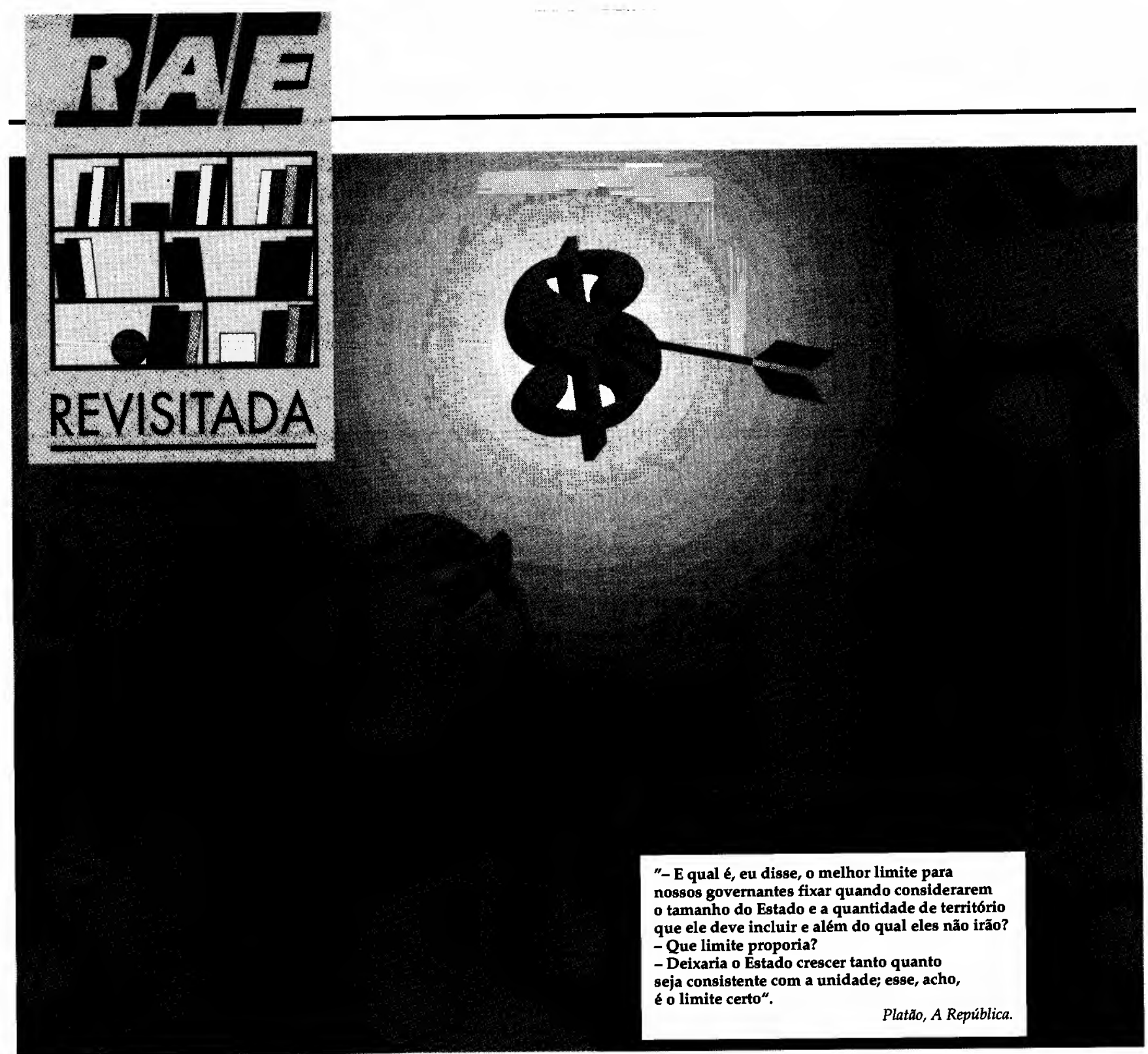

\title{
O MODELO DE CUSTO MÍNIMO NA ADMINISTRAÇÃO DA PRODUÇÃO
}

Claude Machline

Professor Titular do Departamento de Administração da Produção, Logística e Operações Industriais da EAESP/FGV.

* RESUMO: Publicado originalmente em setembro de 1968, este artigo descreve e exemplifica um modelo clássico de custo mínimo que encontra numerosas aplicações em administração industrial, tais como: estruturação organizacional, compras, gestão de estoques, programação da produção, controle de qualidade, manutenção, logistica, dimensionamento da linha de produtos, nível de serviço e outras. Neste versátil modelo, dois custos apresentam tendências opostas e a solução razóavel para a minimização do custo total situa-se num ponto intermediário entre as duas posições extremas.
* PALAVRAS-CHAVE: Modelos, administração da produção, custo minimo, tomada de decisão.

* ABSTRACT: Originally published in the September 1968 $R A E$ issue, this paper describes, illustrating it with examples, a classical minimum cost model, which finds application in many industrial administration situations, such as: organizational structuring, purchasing, inventory management, scheduling, quality control, maintenance, logistics, product line dimensioning, service level and others. In this versatile model, two costs display opposite trends, and the solution for total cost minimization lies somewhere betwen the two extreme possible positions.

* KEY WORDS: Models, production management, cost minimization, decision making.

São Paulo, 33(2):76-89

Mar./Abr. 1992 
O objetivo deste artigo é mostrar a grande aplicação de certo modelo quantitativo, que chamaremos de modelo de custo mínimo, na Administração da Produção.

O administrador está cada vez mais preocupado com a redução de seus custos. Em muitas situações, a gerência já sabe que não pode, simplesmente, escolher a alternativa aparentemente melhor ou, mesmo, basear-se em algum princípio de administração, mas deve calcular o custo total de todas as alternativas possiveis $\mathrm{e}$ selecionar a que apresenta custo menor. As considerações relativas aos custos pareccm suplantar todas as demais, a fim de permitir a sobrevivência $c$ a expansão das empresas. O fato de que o dinheiro é o denominador comum de todos os objetivos $\mathrm{e}$ resultados das gestôes industriais explica porque a alternativa de custo total menor deva ser, como realmente é, tão avidamente procurada.

A construção de um modelo ć tarefa delicada, tanto mais quanto maior for o número de variáveis cm jogo. Porém, em muitas situaçōes, apenas um número restrito de fatores intervém, permitindo a análise quantitativa do problema.

\section{MODELOS}

Um modelo pode ser definido como uma representação da realidade que visa a explicar o comportamento de determinado setor do mundo concreto!.

Os modelos têm sido tradicionalmente classificados em três grupos²:

1. Modelos físicos. Os modelos físicos são os que preservam certas relações físicas dos objetos que representam. São, em geral, construídos em escala. Como excmplos citem-se: plantas, maquetes, fotografias.

2. Modelos análogos. Quando a correspondência entre o objeto e o modelo físico se torna mais abstrata, estamos em presença de um modelo análogo. As representações gráficas, os organogramas, os esquemas de circuito elétrico são exemplos de modelos análogos.

3. Modelos simbólicos ou matemáticos. Os modelos simbólicos são relações matemáticas entre símbolos que representam as variáveis em jogo. As leis fí- sicas constituem exemplos de modelos desta categoria.

O modelo de custo mínimo, do qual trataremos aqui, pertence ao terceiro tipo. Procura explicar a influência de variáveis fundamentais, como, por exemplo, o volume de recursos utilizados, sobre o resultado objetivado, a saber, o custo, grandeza de maior interesse para o administrador.

\section{O custo de estocar é uma reta; o de efetuar as compras, uma hipérbole. 0 custo das matérias- primas, em geral independente da quantidade comprada, pode ser omitido, por não influir na forma da curva do custo total.}

\section{O MODELO CLÁSSICO DO LOTE ECONÔMICO}

O exemplo mais conhecido de modelo de custo mínimo ć o do lote econômico. Foi desenvolvido por F.W. Harris, cm $1915^{3} \mathrm{e}$ é, historicamente, o primeiro modelo criado para representar problemas administrativos.

O modelo do lote econômico é muito empregado em duas aplicações: nos problemas de compras e nos de planejamento da produção. Veremos adiante que este modelo tem aplicações possívcis em muitos outros campos.

O modelo do lote econômico de compras, em sua forma clássica ${ }^{4}$, analisa a influência do tamanho da remessa comprada de cada vez sobre o custo total da compra. Este é a soma dos custos

1. das matérias-primas;

2. de efetuar a compra;

3. de financiamento $c$ armazenamento do estoque.

Comprando-se uma vez por ano, o custo de efetuar a compra é mínimo, porém o custo de financiamento e armaze-
1. BUFFA, Elwood S. Models for production and operations management. Nova lorque: John Wiley and Sons, Inc., 1966.

2. MILLER, David W.; STARR Martin K. Executive decisions and operations research. Englewood Cliffs, New Jersey: Prentice-Hall, Inc., 1961.

3. HARRIS, F. W Operations and costs (Factory Management Series). Chicago: A.W. Shaw Co., 1915.

4. PRICHARD, J.W.. EAGLE, R. $\mathrm{H}$. Modern inventory management Nova lorque: John Wiley and Sons, Inc., 1965; ZACARELLI, Sergio B. Flanejamento e controle da produçäo. Sào Paulo: Pioneira, 1967. 
namento é máximo. Comprando-se muitas vezes por ano, a relação entre esses dois custos se inverte. Haverá uma política de compra que permitirá tornar o custo total, soma desses dois pontos, o mais baixo possível. A quantidade correspondente a esse custo total mínimo é o lote econômico de compras. A figura 1 é a representação gráfica do modelo em foco. Note-se a existência de dois custos de crescimento oposto: um deles, o custo de estocar, igual a

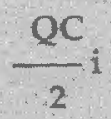

cresce com o número $Q$ de peças por lote, (C é o preço de compra unitário da peça e i é a taxa de juros e armazenamento); o outro, o custo de efetuar a compra, igual a decresce com o número $Q$ de peças por lote ( $R$ é número total de peças a serem compradas no ano e P é o custo de efetuar cada compra).

O custo de estocar é uma reta; o de efetuar as compras, uma hipérbole. $O$ custo das matérias-primas, em geral independente da quantidade comprada, pode ser omitido, por não influir na forma da curva do custo total. Este, conforme se vê na figura, tem um mínimo, correspondente ao lote econômico de compras, Qe. É fácil provar que o lote econômico ocorre no ponto de cruzamento dos dois custos analisados acima e que essa propriedade se verifica sempre que estamos em presença de um custo proporcional e de outro inversamente proporcional à variável analisada.

O modelo do lote econômico de produção, parecido com o anterior, analisa a influência das diversas maneiras de se processarem as ordens de produção de determinado produto, a saber, uma vez por ano, duas vezes por ano, e assim em seguida, sobre o custo total de fabricação; esta é a soma dos custos

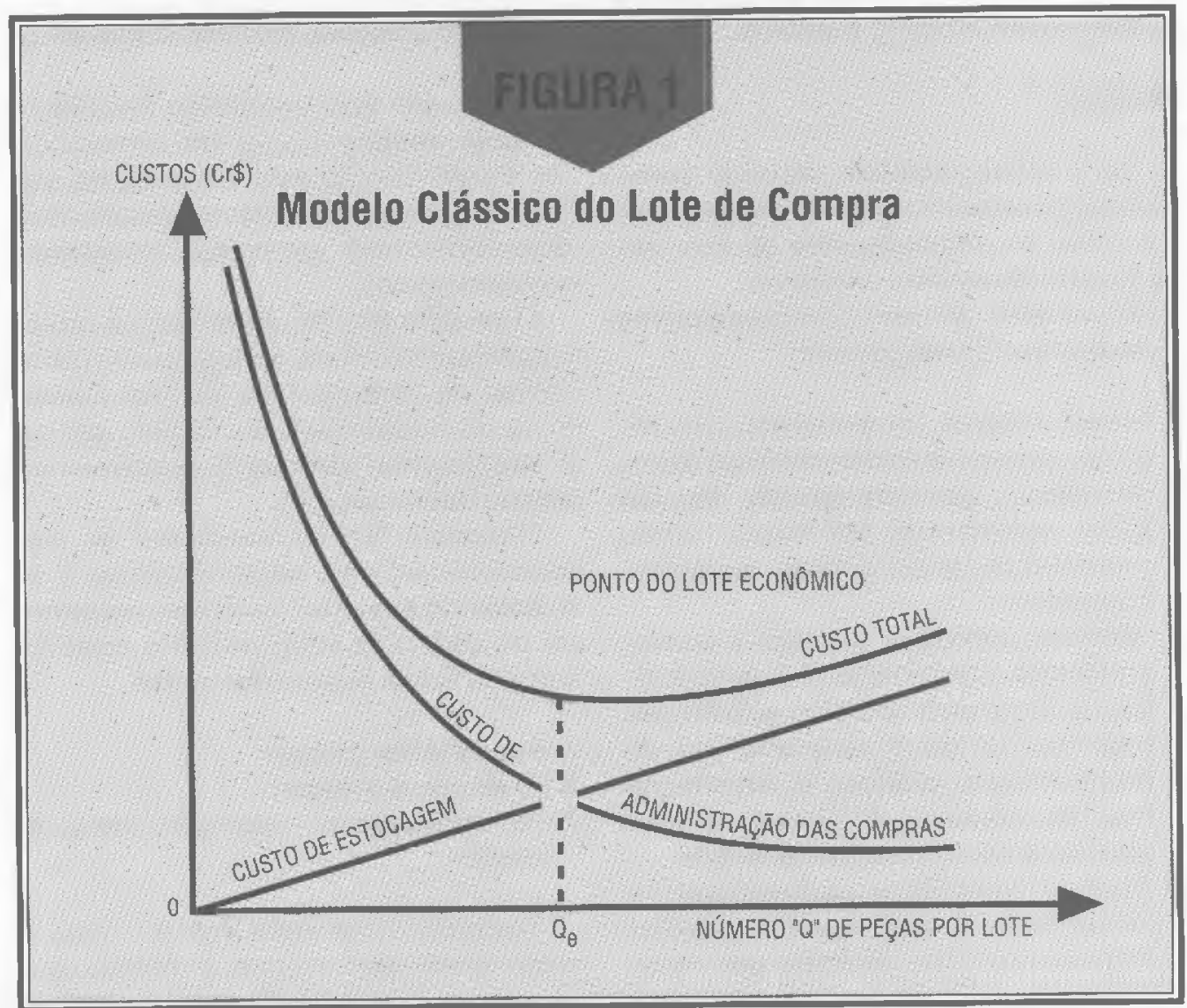


1. de produzir as peças;

2. de preparar as máquinas;

3. de manter estoque de produtos acabados.

Ao custo total mínimo corresponde o lote econômico de fabricação ${ }^{5}$.

Ambos os modelos de lote econômico chegaram a ser muito usados na indústria, principalmente em firmas norteamericanas, na década de 30 . Estão sendo agora menos utilizados do que antes, em parte devido ao custo elevado da administração dos próprios modelos, que exige a atualização anual dos cálculos, e, também, devido ao fato de que certos pressupostos do modelo, como, por exemplo, a previsibilidade do consumo anual, não se verificam na realidadé.

A despeito das críticas feitas aos modelos, e que encontram vigoroso portavoz em Burbidge ${ }^{7}$, verificou-se intenso desenvolvimento teórico relativamente a esse problema, tendo muitos autores criado verdadeira profusão de modelos, deterministicos uns e probabilísticos outros, que levam em conta diversas variáveis, como por exemplo, a influência de descontos nos preços, da variação da demanda, de flutuaçóes na regularidade das entregas, de interferência com os demais produtos existentes no estoque, de limitaçŏes de capital de giro e, ainda, de outros fatores ${ }^{8}$.

\section{MODELO DO NÍVEL ECONÔMICO DE INSPEÇÃO}

Outro modelo quantitativo sugerido há muitos anos na literatura especializa$\mathrm{da}^{4}$ e que apresenta semelhanças com o modelo do lote cconómico ó o do nível econômico de inspeção. Vamos ilustrá-lo com um exemplo, relativo ao número mais adequado de inspetores.

Alguns anos atrás, numa fábrica paulista de caixas de papelāo ondulado, a Diretoria de Vendas, impressionada com 0 problema das rejeiçōes e reclamaçóes dos clicntes, exigiu a criaçăo de um Departamento de Controle de Qualidade. A Chefia de Produção ficou muito infeliz com a exigência e combateu a idéia, argumentando que a criação do novo setor iria aumentar os custos c não reduziria o refugo. A discussão descambou rapidamente para o domínio emotivo, gerando conflitos que comprometeram, durante meses, o êxito do setor recém-criado.

Entretanto, o problema deveria ter sido examinado sob um ângulo mais científico, da maneira que vamos apresentar, beneficiando-nos da experiência a posteriori, adquirida pela vivência com esse caso.

\begin{tabular}{|c|} 
O efeito psicológico resultante \\
da presença, temível, do inspetor, \\
conjugado com o impacto criado \\
pela notícia da iminente criação \\
de um Departamento de Controle \\
de Qualidade, resultou em maiores \\
cuidados por parte dos operários \\
e maior zelo por parte dos \\
contra-mestres.
\end{tabular}

O refugo total, somando-se as perdas em todas as fases da produção, podia ser estimado, na falta de dados precisos, em $25 \%$ do papelão fabricado, incluindo-se uma percentagem de $10 \%$ de defeituosos que seguiam para os clientes. Isso incluía defeitos graves, médios e leves. A nomeação de um inspetor volante, medida de emergência que a Chefia de Produção não pôde adiar por mais tempo, devido à insistência do Diretor de Vendas, resultou num decréscimo imediato do refugo, que caiu para $20 \%$, na base de tomada de amostras. $\mathrm{O}$ efeito psicológico resultante da presença, temivel, do inspetor, conjugado com o impacto criado pela notícia da iminente criação de um Departamento de Controle de Qualidade, resultou em maiores cuidados por parte dos operários e maior zelo por parte dos contramestres; os defcitos mais chocantes como: manchas causadas pelos sapatos sujos dos operários pisando as caixas de papelão, oul estragos mecânicos provenientes de manipulação brutal das caixas, começavam a sumir. Com a nomeação de um chefe de Inspeção e de cinco inspetores volantes que, dia e noite, examinavam, em todas as etapas, os lotes de caixa na base de amostragem estatística, o refugo caiu e fixou-se ao nivel de $15 \%$. Os relató-
5. SCHOEPS, W. Lote econômico de produçăo, conceito e prática. Revista de Administração de Empresas, Rio de Janeiro. $v$ 2. $n^{\circ}$ 4, ago. 1962; MAGEE, John F. Planejamento da produção e controle de estoques. São Paulo: Pioneira, 1967

6. MOORE, F. G. Production Control. Nova lorque: McGrawHill Book Company, Inc., 1961

7. BURBIDGE, John, L. The principles of production control. Londres: Macdonald and Evans Ltd., 1962

8. HANSSMANN, Fred Operations Research in Production and inventory control. Nova lorque: Jolm Wiley and Sons Inc. 1962: MACHLINE. Claude. Lote econômico de compras e inflaçâo. Revista de Administração de Empresas. Rio de Janeiro: FGV, vol. 1. n" 1. ago 1961

9. JURAN, J. M. Quality control handbook. Nova lorque: McGraw-Hill Book Company. Inc., $2^{2}$ ed. 1962 


\section{Quadro 1: Custos de Diversos Níveis de Inspeção}

\begin{tabular}{lcccc}
\hline $\begin{array}{l}\text { NIVEIS DE } \\
\text { INSPEÇÃ0 }\end{array}$ & $\begin{array}{c}\text { Percentagem } \\
\text { de refugo }\end{array}$ & $\begin{array}{c}\text { Custo do refugo } \\
\text { mensal (direto) (Cr\$) }\end{array}$ & $\begin{array}{c}\text { Custo dos } \\
\text { inspetores (Cr\$) }\end{array}$ & $\begin{array}{c}\text { Custo } \\
\text { total (Cr\$) }\end{array}$ \\
\hline A. Nenhum inspetor & $25 \%$ & $120.000,00$ & 0,0 & $120.000,00$ \\
\hline B. 1 inspetor volante & $20 \%$ & $96.000,00$ & 800.00 & $96.800,00$ \\
\hline C. 5 inspetores volantes e 1 chefe & $15 \%$ & $72.000,00$ & $6.000,00$ & $78.000,00$ \\
\hline 0. 10 inspetores e 1 chefe & $15 \%$ & $72.000,00$ & $10.000,00$ & $82.000,00$ \\
\hline
\end{tabular}

rios de inspeção mostraram que os defeitos de fabricação, tais como: colagem e grampeação defcituosa, má impressião, fora de esquadro etc., estavam reduzidos ao mínimo, sendo que o refugo que năo se podia mais eliminar era devido a matérias-primas, papel c cola; a reduçào posterior do refugo só poderia ser obtida com melhoria das materias-primas.

O quadro 1 representa os custos das diversas alternativas que se ofereciam aos dirigentes dessa empresa. () custo total, coluna 5, à direita, é a soma do custo do refugo (coluna 3 ) e do custo da inspeçào (coluna 4). A melhor alternativa é obtida quanto o custo total é mínimo. Esse é o nível ótimo de inspeção.

A figura 2 representa graficamente o quadro 1. Esse tipo de gráfico é extremamente comum nas mais diversas situa-

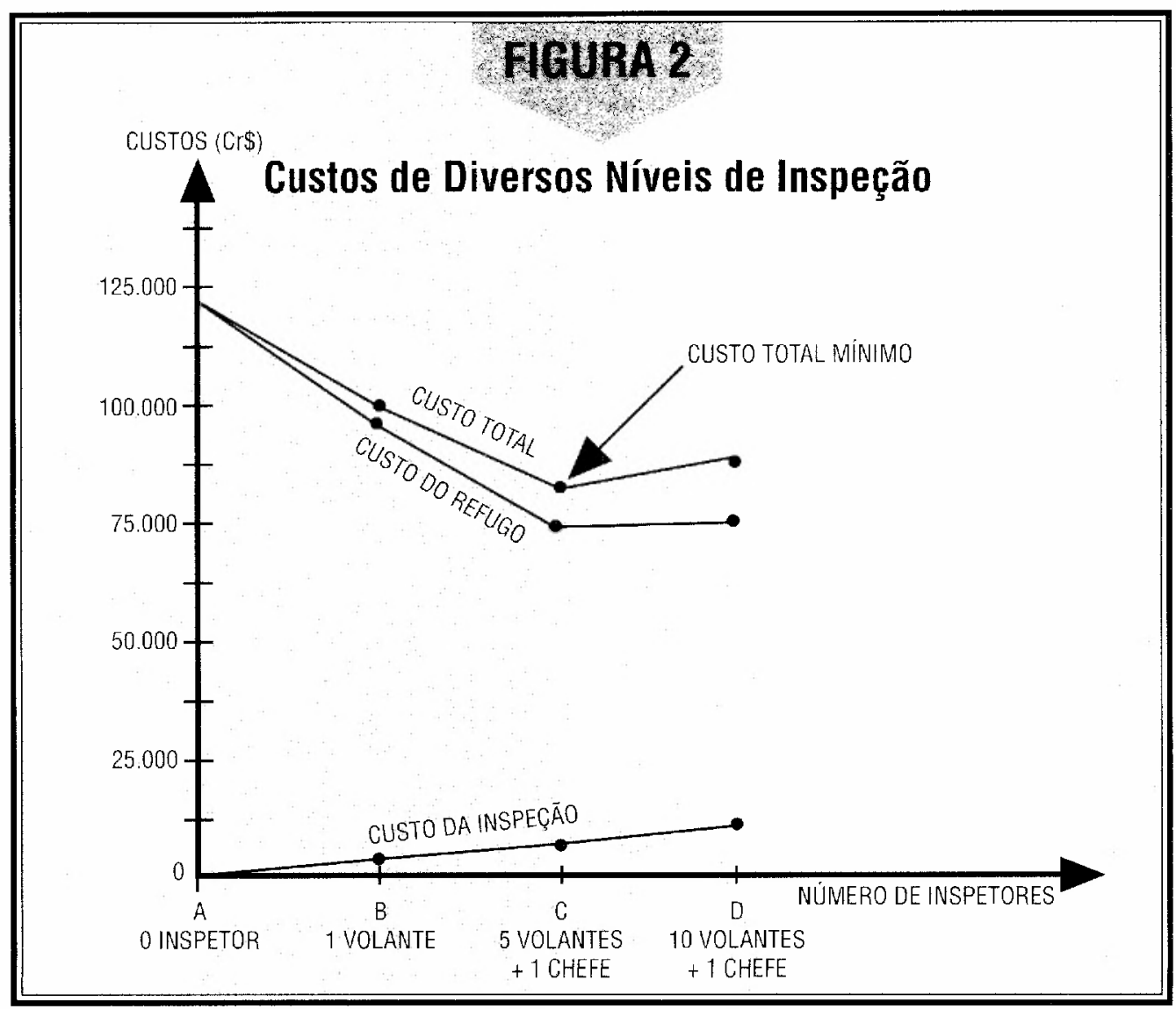


ções administrativas, quando há dois custos opostos (caso do lote econômico de compras, por exemplo). Vemos que há duas tendências contraditórias: nenhuma inspeção custará caro em termos de refugo; muita inspeção custará caro em termos de salários. A determinação do ponto mais econômico deve ser tentada, por estimativa dos dados, classificando as causas das perdas e avaliando a sua eliminação pela presença de determinado número de inspetores.

Notemos que os custos indiretos do refugo não entraram em cogitação neste modelo simplificado.

Vários autores, entre eles Juran ${ }^{10}$, já tinham sugerido um modelo como o da figura 2. Cremos que o caso apresentado constitui exemplo concreto de validação desse modelo.

O modelo precedente é menos popular do que o do lote econômico, primeiro, porque não tem a mesma generalidade do que aquele, segundo, porque não é suscetível de ser representado por expressões matemáticas. Porém, é possível, em cada caso, calcular as variações dos custos em função da variável: número de inspetores.

Problema semelhante é o da conveniência de se ter um sistema de custos de grande precisão, porém caro, ou de optar por um sistema de menor exatidão, menos dispendioso. Há um conflito entre o custo de apuração e o apuro dos custos, sendo uma solução intermediária, que forneça um custo aproximado, muitas vezes a mais conveniente.

Como outro exemplo, relacionado com o nível econômico de inspeção, citemos o seguinte, ilustrativo de uma série de situações administrativas freqüentes.

A escolha entre a adoção de:

1. inspeção total;

2. inspeção estatística e

3. nenhuma inspeçāo, constitui uma das decisões mais freqüentes que o administrador do Controle de Qualidade deve tomar, em relação às características de qualidade de produtos comprados, em processo e acabados. $O$ chefe do Controle de Qualidade deve sempre lembrar-se de que o objetivo final do seu trabalho é procurar satisfazer economicamente as exigências de qualida- des do consumidor. Inclusive, a preocupação econômica está, implicitamente, em grande evidência nos planos Dodge-Romig e Military Standard ${ }^{11}$.

Numa fábrica paulista de produtos farmacêuticos, na seção de verificação de ampolas, o procedimento-padrão consiste em inspecionar duas vezes, na sua totalidade, as ampolas de injeção, antes de sua embalagem final e seu despacho aos clientes. Anos atrás, efetuavam-se três inspeções $100 \%$ consecutivas. Discute-se, na empresa, a conveniência de voltar a fazer três inspeções $100 \%$, seguidas de uma reinspeção estatística. A alternativa mais indicada deve ser obtida por meio de raciocínio quantitativo.

A experiência demonstrou que o nível de refugo na inspeção dessas ampolas é de $10 \%$, sendo que alguns lotes chegam a ter $20 \%$ de defeituosos. Uma inspeção $100 \%$ reduz os defeitos ao nível de $0,1 \%$, pois nerhuma inspetora consegue eliminar todas as ampolas defeituosas. Uma segunda inspeção $100 \%$ reduz o número de defeitos a $0,01 \%$ e uma terceira inspeção $100 \%$ ao núvel de $0,002 \%$. Os lotes de ampolas são fabricados na base de 10.000 unidades/dia. Admitiremos que o custo de inspeção de uma ampola é de $\mathrm{Cr} \$ 0,0005$ e que o custo de deixar passar uma ampola defeituosa, em vista das reclamações possiveis, é de $\mathrm{Cr} \$ 10,00$.

Calculamos a seguir os custos totais diários de diversos métodos de inspeção:

\section{Nenhuma Inspeção}

- Custo de inspeção =0

- Custo de deixar passar peças defeituosas: $10.000 \times 10 \% \times 10,00=\operatorname{Cr} \$ 10.000,00$

Custo total $=\operatorname{Cr} \$ 10,000,00$

\section{Uma inspeção $100 \%$}

- Custo da inspeção $=10.000 \times 0,005=$ $\operatorname{Cr} \$ 50,00$

- Custo de deixar passar peças defeituosas: $10.000 \times 0,1 \% \times 10,00=\mathrm{Cr} \$ 100,00$ Custo total $=\operatorname{Cr} \$ 150,00$
10. Idem, ibidem.

11. GRANT, Eugene L. Statistical Quality Control. Nova lorque: McGraw-Hill Book Company, Inc., $3^{\sharp}$ ed., 1965. 


\section{Duas inspeções $100 \%$}

- Custo da inspeção $=10.000 \times 0,005$ t $9.000 \times 0,005=\mathrm{Cr} \$ 100,00$

- Custo de deixar passar peças defeituosas: $10.000 \times 0,01 \% \times 10,00=\mathrm{Cr} \$ 10,00$

Custo total $=\operatorname{Cr} \$ 110,00$

\section{Três inspeçổes $100 \%$}

- Custo da inspeção $\cong 30.000 \times 0,005 \equiv$ Cr $\$ 150,00$

- Custo de deixar passar peças defeituosas:

$10,000 \times 0,002 \% \times 10,00=\mathrm{Cr} \$ 2,00$

Custo total $=\operatorname{Cx} 152,00$
Vê-se que essa fábrica está procedendo corretamente ao realizar duas inspeções totais do produto acabado.

Uma inspeção estatística, entretanto, seria aconselhável pelo seguinte motivo prático: é difícil administrar duas inspeções totais sucessivas. Por mais cuidado que se tome, há o perigo de confundir lotes ainda não inspecionados com lotes já inspecionados e, também, devido à monotonia desse trabalho, de que, uma vez ou outra, as inspetoras não realizem uma inspeção cuidadosa.

Parece-nos recomendável, pois, nesse caso, que, após as duas inspeções $100 \%$, se proceda à tomada de uma amostra diária, por exemplo, valendo-se de um plano de inspeção estatística do tipo Dodge-Romig ${ }^{12}$ que assegure um LTPD (lot tolerance per cent defective ou percentagem defeituosa tolerada no lote) de $0,01 \%$.

A figura 3 mostra a forma das funções

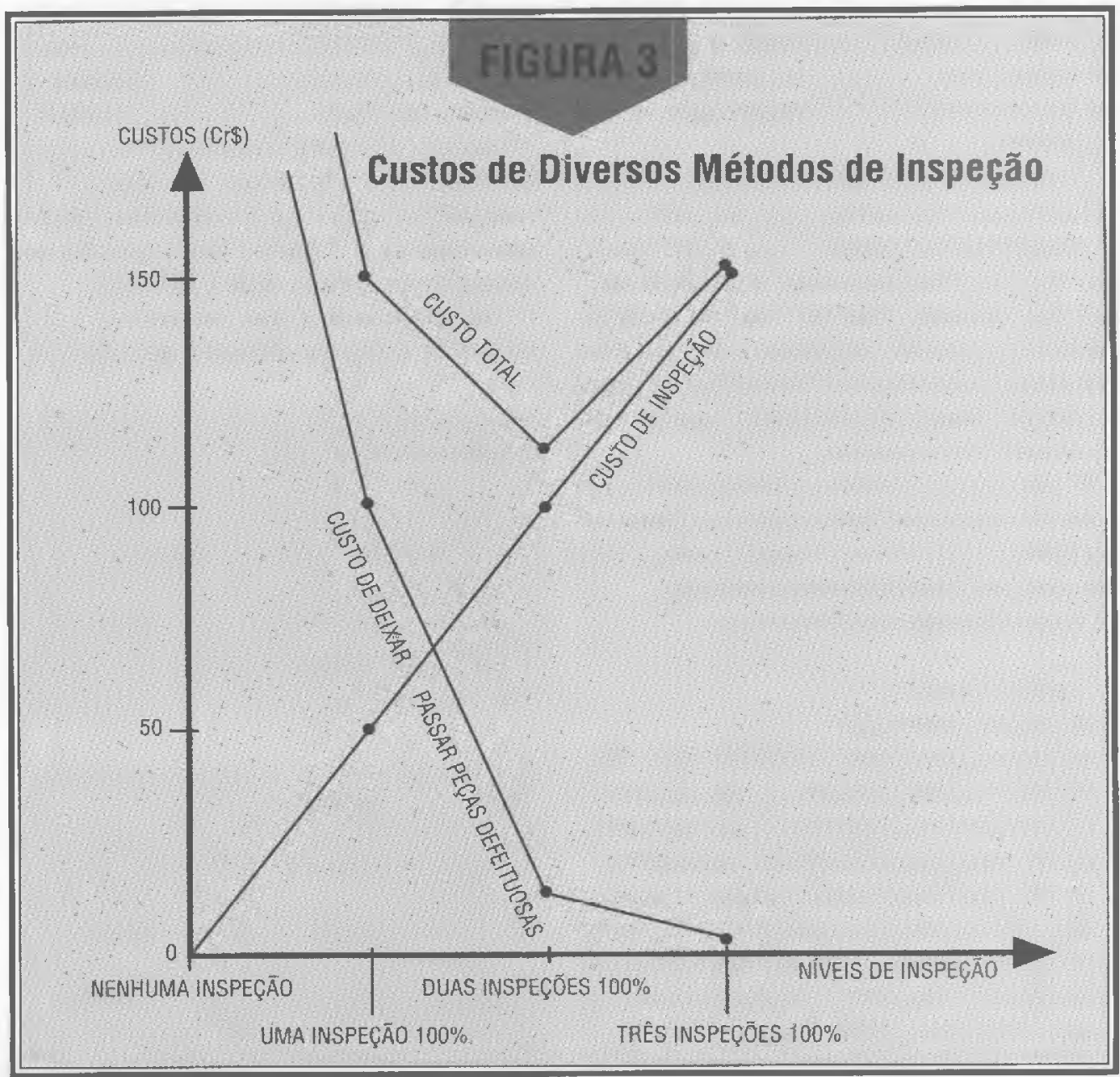


representativas dos custos, para o modelo estudado.

\section{MODELO DE NIVEL ECONÔMICO DE PADRONIZAÇÃO DE LINHAS}

Examinaremos agora outras aplicações do modelo de custo mínimo em diversos setores da Administração da Produção. São numerosas as situações nas quais o dirigente se defronta com dois custos antagônicos, correspondentes a duas tendências contraditórias que precisam ser conciliadas. A única maneira de resolver o dilema é encontrar o ponto correspondente ao custo total múnimo. Vejamos inicialmente o problema da padronização das linhas de produção.

A produção de muitas indústrias é composta de dois tipos básicos: os produtos de linha, ou padronizados e os produtos especiais, ou de encomenda. Assim, por exemplo, uma fábrica de máquinas agrícolas monta secadores, catadoras, silos etc., de modelos e capacidades determinados, que constituem a série normal de fabricação; e pode também, a pedido, fazer essas máquinas em modelos e capacidades especiais, para atender a clientes que necessitam de equipamentos diferentes. $\mathrm{Da}$ mesma forma, as fábricas de condicionadores de ar, as usinas siderúrgicas, as fábricas de tintas e, praticamente, quase todas as indústrias, são solicitadas a manufaturar produtos de linha e produtos especiais.

A padronização consiste na eliminação de produtos especiais. A diminuição do número de peças e produtos diversos fabricados acarreta redução nos custos dos estoques, de preparação de máquinas e de supervisão. A padronização excessiva pode, porém, ser prejudicial, pois o produto padronizado não se adapta quase nunca perfeitamente ao desejo do cliente ou às suas especificações. Será necessário maior esforço de vendas para convencer o cliente a aceitar o produto, o que se traduz por um custo de vendas maior. Teremos, em conclusão, dois custos opostos, o de diversificação e o de padronização; o primeiro cresce e o segundo decresce com a variedade de produtos fabricados.

A forma geral do modelo de padronização é representada na figura 4. A lição a se tirar desse modelo é que a diversificação e a padronização extremas podem levar a custos maiores do que uma solução de compromisso.

Via de regra, uma extrema dispersão na linha de fabricação é revelada por uma análise do tipo "A.B.C.". Esta consiste em calcular a percentagem que cada produto representa nas vendas totais. Os produtos que correspondem a $1 \%$ ou $2 \%$ das vendas e sem potencial previsível futuro proporcionarão muitas vezes, por sua supressão, grande redução do custo de diversificação e pequeno aumento do custo de padronização. A atenção que exigem por parte da administração não compensa as vendas; a especialização se impõe, é quase certo que um pequeno esforço de vendas permitirá compensar os produtos de pequena expressão pelos das linhas mestras, a um custo menor. (Ver figura 4).

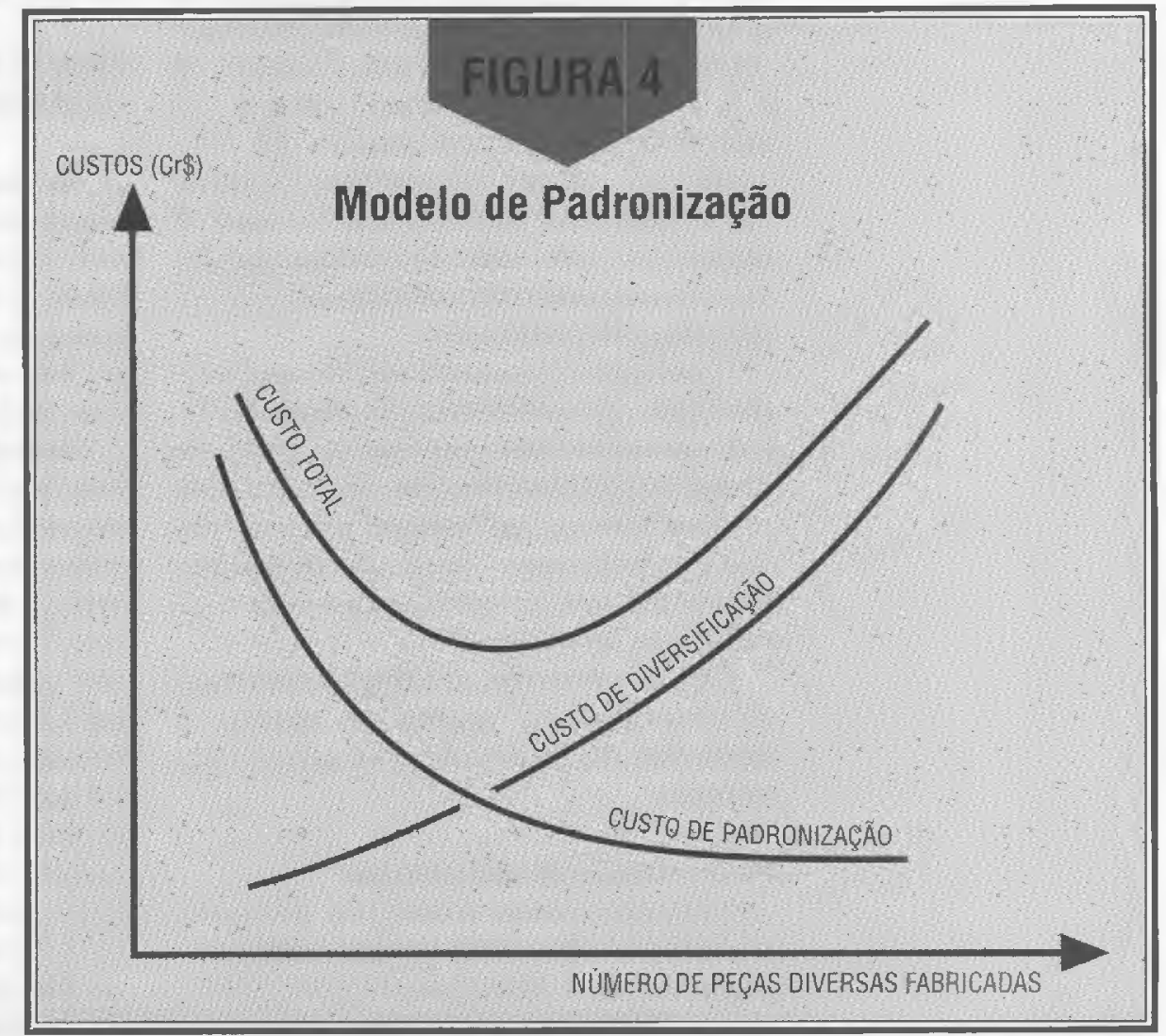




\section{MODELO DO NIVEL ECONÔMICO DE PADRONIZAÇÃO DE SÉRIES}

Problema estreitamente relacionado ao anterior é o da padronização das séries de produtos.

Uma série industrial é um conjunto de peças de mesmo tipo, diferindo entre si pelo tamanho. Os formatos de desenhos industriais e de impressos, e as embalagens de diversas capacidades de um mesmo produto constituem exemplos de séries.

Examinemos o caso de um laboratório de produtos farmacêuticos que utiliza seis tamanhos de ampolas de injeção de água destilada, respectivamente de 20 $\mathrm{cm}^{3}, 10 \mathrm{~cm}^{3}, 6 \mathrm{~cm}^{3}, 5 \mathrm{~cm}^{3}, 2 \mathrm{~cm}^{3} \mathrm{e} 1 \mathrm{~cm}^{3}$. A padronização da série, ou simplificação da série, consiste em reduzir o mais possível o número de ampolas, a fim de diminuir a variedade do estoque de vidros, obter economia de escala na compra e simplificar a programação e o controle da produção. A padronização extrema seria alcançada quando existisse apenas uma embalagem, a ampola de 20 $\mathrm{cm}^{3}$. Os custos da padronização são aqui representados pela perda de espaço na ampola. Estágios intermediários de padronização correspondem à retenção de $5,4,3$ ou 2 lipos de ampolas. Um grau razoável de padronização seria o que consistiria em utilizar 4 tamanhos de ampolas, as de $20 \mathrm{~cm}^{3}, 10 \mathrm{~cm}^{3}, 6 \mathrm{~cm}^{3} \mathrm{e} 2 \mathrm{~cm}^{3}$. A figura 4 dá uma idéia da forma das curvas que representam os custos de padronização e diversificação.

Condições para a criação de modelos dos tipos que acabamos de estudar existem em numerosas empresas. $O$ processo decisório envolve poucas alternativas; é, razoavelmente, fácil estimar os custos totais de cada uma, não sendo necessário procurar a função exata representativa da influência da variável.

Outras situações administrativas nas quais se poderia cogitar da criação de modelos de padronização são as seguintes:

\section{Padronização de embalagens}

Uma fábrica de tintas, por exemplo, possui a escolha entre embalar seus produtos em latas litogravadas, com marcações distintas para cada tipo de tinta e cor, e latas simples, sobre as quais se colariam rótulos indicativos do tipo e da cor da tinta. Vemos que possuímos, aqui também, condições para a criação de um modelo quantitativo, com dois custos opostos.

\section{Padronização de impressos}

O formulário mais padronizado de todos é a folha de papel branco, que acarreta, porém, o maior trabalho de preenchimento; à medida que se torna mais específico, o formulário fica mais adequado às necessidades do usuário, porém, há um investimento a ser feito na impressão do formulário especial, o que acarreta maior custo de estoque. Temos, pois, aqui também, um conflito entre dois custos opostos, devendo o administrador encontrar o ponto de custo mínimo, num meio-termo entre a padronização e a especialização extremas dos impressos.

\section{Padronização de frotas de veículos}

Às economias de manutenção e estocagem de peças de reposição se contrapõe o custo de inadequação de veículos padronizados, impróprios para todas as necessidades de transporte da empresa.

\section{MODELO DO NÍVEL ECONÔMICO DE CENTRALIZAÇÃO}

As empresas que operam em vasta extensão territorial ou possuem muitos níveis hierárquicos sempre se interrogam sobre a conveniência de centralizar suas compras, sua manutenção, seu processo decisório ou outra fase qualquer de suas atividades.

Assim, por exemplo, no que tange às compras, a centralização total consistiria em realizar todas as compras na matriz; a descentralização total consistiria em efetuar as compras ao nível de unidades, setores ou filiais; políticas intermediárias consistiriam em autorizar compras locais de certos produtos ou até certos valores, ou dentro de um orçamento setorial. A descentralização proporciona rapidez na decisão, supressão de volumosa correspondência, menor custo de transporte; a centralização permite alcançar preços melhores porque se negocia em maiores quantidades. Uma solução intermediária, com certos produtos 
comprados na sede e outros nas dependências, permitirá, muitas vezes, alcançar um custo total menor.

O custo total é composto do custo de descentralização, que é o custo da não obtenção de descontos nas aquisições, e do custo de centralização, que é o custo dos prejuízos decorrentes da tramitação burocrática dos pedidos.

É possível construir o modelo valendo-se da seguinte análise. Classifiquemos os produtos de consumo adquiridos pela empresa em três categorias: os produtos de classe A são as matérias-primas, os combustiveis e os componentes comprados em grandes quantidades e que representam $75 \%$ das compras totais, em valor; em geral, trata-se de um pequeno número de itens, não mais do que $5 \%$ do número total de itens comprados. Os produtos de classe $B$ são os que perfazem cerca de $20 \%$ das compras totais, em valor; representam, via de regra, uns 15\% do número total de itens comprados; os produtos de classe $C$ são os de pequeno valor total $\mathrm{e}_{r}$ embora representem apenas $5 \%$ do valor das aquisições, são muito numerosos, constituindo até $80 \%$ da variedade de itens comprados.

Este modelo terá a forma da figura 5.

Se descentralizássemos todas as compras, das categorias $\mathrm{A}, \mathrm{B}$ e $C$, teríamos um máximo custo de descentralização e um mínimo custo de centralização. Descentralizando-se somente as compras de categorias $\mathrm{B}$ e $\mathrm{C}$, e centralizando-se as de categoria A, conseguiremos descontos substanciais nas compras vultosas, ao mesmo tempo que evitaremos esperas dispendiosas provenientes dos atrasos na aquisiçăo dos itens $\mathrm{B}$ e $\mathrm{C}$, os quais, embora de pequeno valor monetário, podem, qualquer um deles, causar, quando faltam, onerosas paralisações da produção. Com essa estratégia, o custo total poderá ser merior do que o de outras diretrizes de compras.

Modelos semelhantes ao anterior podem ser construídos para situações de centralização de autoridade, sempre que se contra-

\section{0 princípio do âmbito de controle} estipula que cada chefe deve ter número limitado, relativamente pequeno, de subordinados, para poder exercer chefia eficiente. De fato, à medida que cresce o número

$$
\begin{aligned}
& \text { de subordinados, torna-se mais } \\
& \text { complexa a tarefa do superior. }
\end{aligned}
$$

põem custos de centralização e descentralização. A própria noção de "âmbito de controle administrativo ${ }^{\prime 13}$ fundamenta-se em conceitos de custos opostos. $\mathrm{O}$ princípio do âmbito de controle estipula que cada chefe deve ter número limitado, relativamente pequeno, de subordinados, para poder exercer chefia eficiente. De fato, à medida que cresce o número de subordinados, torna-se mais complexa a tarefa do superior. Graicunas ${ }^{14}$ tentou indicar a forma dessa lei de crescimento; mostrou que as relações de diversas es-
13. GRAICUNAS, V. A. Relationship in Organization. Papers on the Science of Administration. Nova forque: Institute of Public Administration, editado por L. Gulick, 1937.

14. GRAICUNAS, V.A., Op. cit. NEWMAN, William, H. Administrative Action. Londres:Sir Isaac Pitman and Sons, 1958.

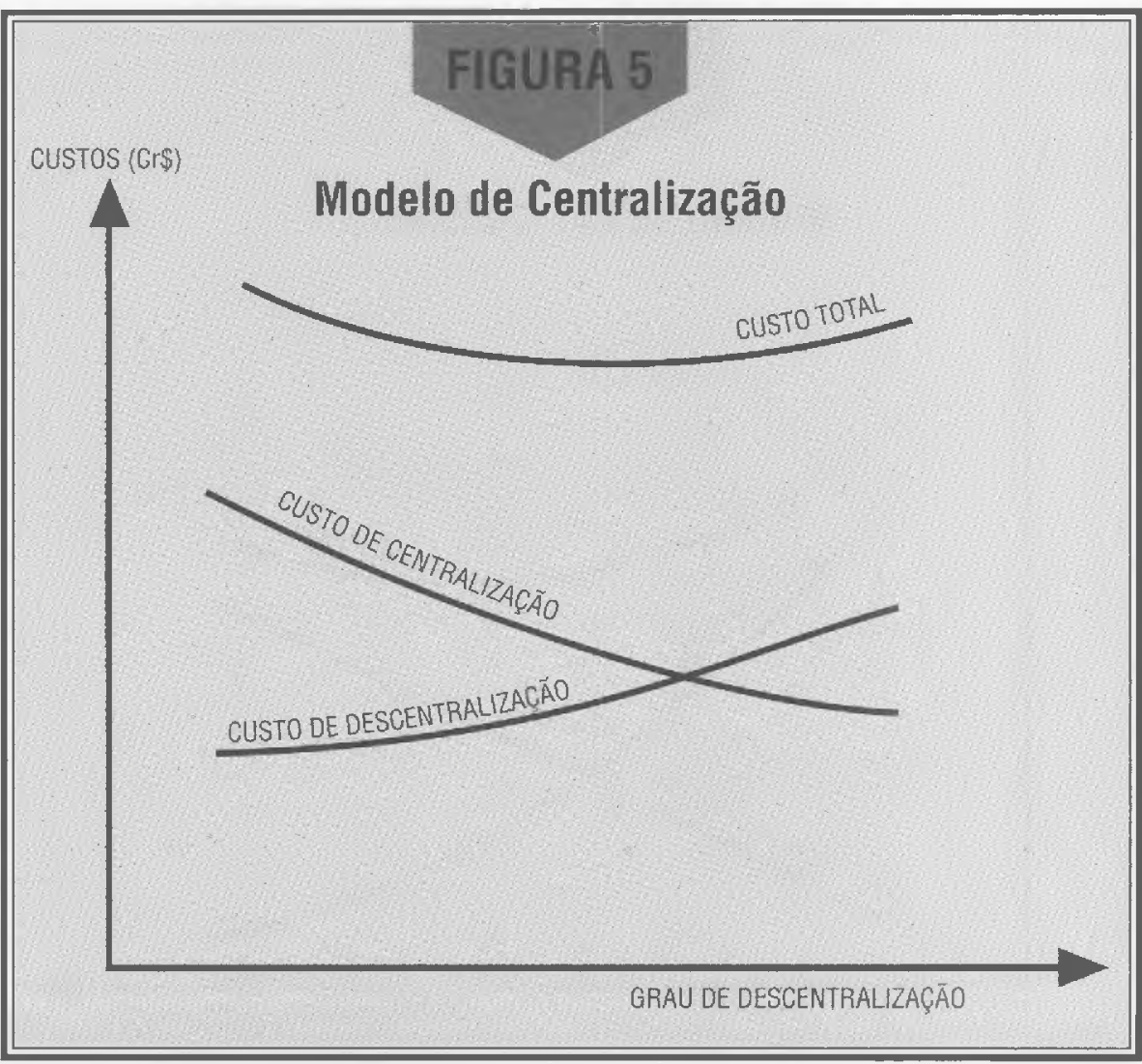


15. CHURCHMAN, C. M:; ACKOFF, R. A.; ARNOFF, E. L. introduction to operations research. Nova Yorki John Wiley and Sons, 1957; SAATY, Thomas L. Mathematical Methods of Operations Research. Nova lorque: McGraw-Hill, 1959 MORSE, Philip M. Quenes, Inventories and Maintenance. Nova York: Wiley and Sons, 1958.

16. KAUFMANN, A., FAURE, R. Invitation a la Recherche Operationnelle. Paris: Dunod, $2^{\mathrm{a}}$ ed. 1966; SASIENI, M. YASPAN, A.; FRIEDMAN, L. Operations Research, Methods and Pro blems. Nova lorque, John Wiley and Sons., INC., KELLY, J. L'entretien prèventif est-i! justifié? Revue de la SOFRO, $n^{0} 10, \mathrm{~Pa}-$ ris: Dunad. pécies entre chefe e subordinados aumentam muito rapidamente com o número de homens. Vamos admitir um crescimento exponencial da tarefa do chefe e, portanto, do custo dessa tarefa, medida em desgaste ou ineficiência; quanto ao custo da chefia, medido pela relação

$\frac{\text { salário do chefe }}{\text { número de subordinados }}$

decresce aproximadamente segundo o inverso do número de subordinados. Temos então, aqui também, uma luta entre custos opostos, salientando-se um ponto de custo mínimo, correspondente ao âmbito de controle conveniente.

\section{MODELOS DE MANUTENÇÃO}

Existem numerosas situações que dizem respeito à administração da manutenção, nas quais encontramos novamente a presença de dois custos de efeitos opostos entre si. São os problemas enfrentados pelas empresas que precisam decidir o número conveniente de mecânicos e de postos de serviços para $o$ atendimento de suas frotas de veículos. Se houver muitas facilidades disponíveis, o custo do atendimento, isto é, o investimento e o custo da mão-de-obra ocasionalmente ociosa são elevados; se houver poucas facilidades, o custo de espera será considerável. Haverá, pois, um ponto ótimo, correspondente ao custo total mínimo (figura 6). Essa problemática foi exaustivamente estudada, tanto por um número finito quanto para um número infinito de "clientes" e para diversas leis de chegada e de saída. É mesmo, pode-se dizer, um dos assuntos mais explorados em Pesquisa Operacional ${ }^{15}$. Modelos mantemáticos foram desenvolvidos com rigor para muitos casos, constituindo a "teoria das filas de espera". (Ver figura 6).

Outro problema de manutenção que dá origem a situação de custos opostos é a questão da conveniência da manutenção preventiva. Se deixarmos correr muito tempo entre as revisões, seremos sujeitos a elevados custos de interrupção na ocasião das quebras de peças; mas se exagerarmos na frequiência das revisóes e das trocas preventivas de peças, teremos custos excessivos de reposição. Portanto, há um ponto ideal, um meio-termo entre a manutenção preventiva e a corretiva. Devem-se conhecer a lei da falha da peças e os custos de troca, de reposição e de interrupção. Diversos modelos já têm sido estuda$\operatorname{dos}^{16}$

Relacionado com o precedente é o problema da determinação do número de oficinas mais conveniente para uma empresa de transporte. As alternativas são uma oficina central ou diversas oficinas espalhadas pelo território servido. $O$ custo fixo de muitas oficinas é alto, mas o custo variável de uma oficina central é considerável, devido ao transporte do veículo quebrado até a sede. O problema de centralização dos almoxarifados numa grande fábrica, e o de pools de serviços de escri- 
tórios são semelhantes.

Ainda no setor de manutenção, um problema dos mais estudados é o da renovação dos equipamentos de desgaste progressivo, como máquinas ou veículos. Se conservarmos muito tempo um equipamento, os custos de manutenção crescem de ano para ano; se o trocarmos amiúde, os custos de investimento são proibitivos. Defrontamo-nos, ainda aqui, com dois custos opostos, conforme a figura 7. O modelo quantitativo correspondente foi exaustivamente estudado na literatura sobre Engenharia Econômica ${ }^{17}$. O método de análise consiste em computar os custos anuais de investimento e de operação, para as alternativas de conservação do equipamento por 1, 2, 3 e mais anos, e optar pelo número de anos para o qual o custo total for menor.

\section{MODELOS DE DISTRIBUIÇÃ̃ E TRANSPORTE}

O setor de distribuição e transporte é rico em situações que se prestam à análise do tipo do custo múnimo.

Uma ilustração é o abastecimento de filiais. Se o depósito central enviar remessas muito grandes às filiais, $o$ investimento em estoque será elevado; se enviar pequenas remessas com freqüuencia, o custo administrativo do despacho e o transporte serão altos. A situaçāo lembra a do lote econômico de $\operatorname{compras}^{18}$.

O tamanho do território que deve ficar sob a jurisdição de cada filial é outro tema que fornece um modelo de custo mínimo ${ }^{19}$. Se o território for muito vasto, o custo do atendimento aumenta; se for reduzido, os custos fixos são excessivos.

\section{OUTROS MODELOS DE CUSTO MÍNIMO}

O modelo de custo mínimo apresenta numerosas outras aplicações industriais, das quais nos contentaremos em enunciar algumas. Mesmo que não seja possível estabelecer em todos os casos as for- mas exatas das curvas de custos, é importante que o administrador esteja consciente da existência de duas tendências opostas, o que lhe permitirá evitar cair num erro extremo.

Muitos problemas de Engenharia Econômica envolvem a seleção da alternativa de custo total mínimo, entre diversos equipamentos tecnicamente viáveis. Se ordenarmos essas alternativas, segundo seu grau de mecanização, poderá ocorrer que, para determinado nível de produção, a alternativa mais econômica se encontre em algum ponto entre a mecanização extrema e a operação puramente manual.

Outro caso em tela é o problema do adiantamento e do pagamento do pessoal. Pagando-se uma só vez por mês, e sem realizar adiantamento, a empresa ganha juros e economiza tempo da Seção de Pessoal, porém enfrenta custos de mávontade por parte dos funcionários ou então custos de atendimento a freqüentes pedidos de empréstimo; pagando duas vezes por mês, talvez obtenha mellhor configuração dos dois custos em jogo, resultando daí um custo total menor.
17. GRANT, Eugene L., Principles of Engineering Economy. Nova York: The Ronald Press Company, 1950; TERBORGH, G. Dynamic Equipment Policy, Nova lorque: McGraw-Hill Book Company, 1949; THUESEN, H. G., Engineering Economy. Nova Yorque: Prentice-Hall, 1950.

18. MACHLINE, Claude. Técnica de Distribuição. Transporte Moderno. São Paulo: Abril, nov. 1967.

19. BOWMAN, Edward H., FETTER, Robert B. Analysis for Production Management. Homewood, Illinois, Richard D. lewin, 1957.

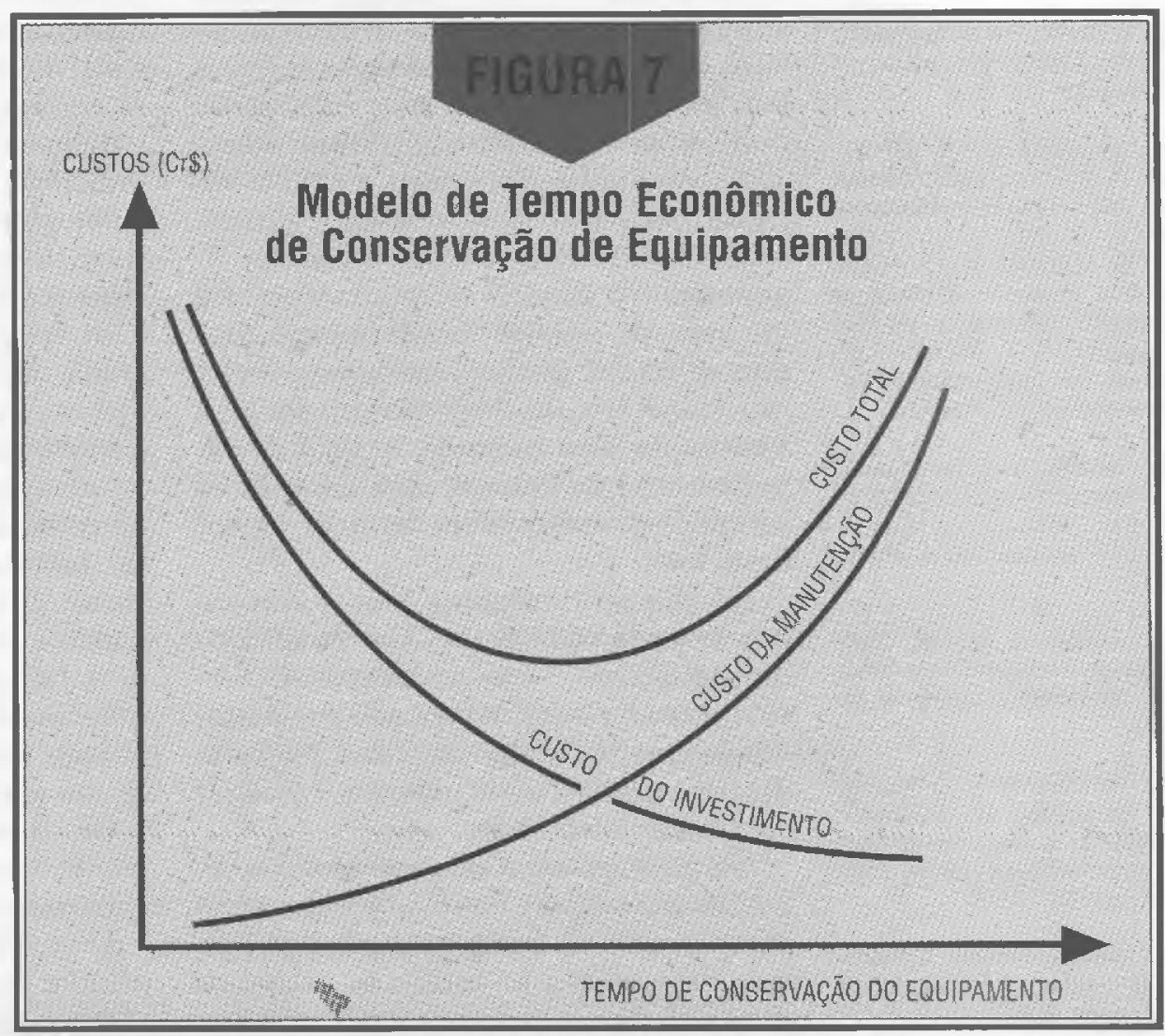


20. GENARI, Breno. Introdução ao PERT básico. Rio de Janeiro: FGV, 1966.

21. SÁ MOTTA, Ivan de. A Prảtica do lote econômico. Revista de Administracāo de Empresas Rio de Janeiro, v. $5, n^{0} 17$, dez 1965; NORTON, Paul T., Engi neering Economy, Handbook of Industrial Engineering and Management, W. G. Ireson e E. L. Grant, ed., Englewood Cliffs: Prentice Hall, Inc. 1955.

22. STARR, A. T. Generation, Transmission and Utilization of Eletric Power. Londres: Sir Isaac Pitman and Sons, $3^{\underline{a}}$ ed., 1953.

23. GARMO, E. Paul de. Engineering Economy. Nova Yrok: The MacMillan Company, $4^{3}$ ed. 1967.

24. WALKER, W. H. LEWIS; W. K. MCADAMS, W. H.; GILLILAND, E. R. Principles of Chemical Engineering. Nova York: McGraw-Hill, 1937.

25. SIMON, Herbert. Administrative Behavior. The MacMillan Company, 1958.

\section{0 raciocínio que consiste em}

definir exatamente as alternativas

e calcular os diversos custos, para

cada alternativa, será sempre mais

utilizado, tornando-se cada vez

mais técnica a função do

administrador profissional.

Na determinação do número mais apropriado de fornecedores, temos também que considerar, de um lado, a obtenção de descontos, para compras em maior quantidade e, do outro lado, o risco resultante de se ficar na dependência de um único fornecedor.

O planejamento de projetos pelo método do caminho crítico consiste, essencialmente, em dosar o ritmo da obra de modo a se obter o custo múnimo, através do balanço entre custos fixos e custos variáveis ${ }^{20}$.

Aliás, não é somente na área de Produção que o modelo encontra aplicações. Apresentaremos um exemplo de "lote econômico de finanças": as Bolsas de Valores cobram das Sociedades Corretoras e das Sociedades cotadas no pregão taxas destinadas a constituir um fundo de seguro. A escolha dos títulos públicos de renda fixa nos quais se investem essas receitas é decidida por uma Comissão Financeira. Se esta só se reunir uma vez por mês, as receitas ficarão muitos dias sem aplicação, perdendo-se juros e correção monetária do dinheiro ocioso. Se a compra for feita cada dia, o custo de administração da compra será elevado. A compra semanal poderá ser a de menor custo total.

No campo financeiro, temos ainda o que se pode chamar de "lote econômico de prestações". Se as prestações não forem consideráveis, talvez seja mais econômico sacrificar algo em juros, pagando diversas prestaçôes de uma vez, e poupar custos administrativos.

Não tem passado despercebida ${ }^{21}$ a semelhança existente entre o modelo de lote econômico de compras e a Lei de Kelvin. Esta última se refere ao diâmetro mais econômico de um condutor elétrico: se for muito fino, o investimento inicial será pequeno, mas as perdas de energia serão consideráveis; o custo total possui forma parecida com a do lote econômi$\mathrm{Co}^{22}$. Em Engenharia Civil e Química muitos problemas de dimensionamento econômico apresentam conformação do mesmo tipo. Citemos alguns: comprimento econômico de arcos de ponte, altura econômica de arranha-céus ${ }^{23}$, ciclo ótimo de limpeza de evaporadores, número mais apropriado de placas nas colunas de destilação ${ }^{24}$. É uma constatação animadora observar que muitas situações administrativas e técnicas envolvem um número pequeno de fatores determinantes de custo e que um modelo relativamente simples permite descrever o custo total em função das alternativas consideradas.

\section{MODELOS E PRINCÍPIOS}

A té o início do século, a Administração de Empresas era atividade essencialmente empírica. Os primeiros autores que se dedicaram ao estudo sistemático dos problemas de administração enunciaram numerosos princípios, tais como o princípio de unidade de chefia, o de definição de funções, o de controle, o de paridade entre responsabilidade e autoridade, e muitos outros. A partir de 1930, verificou-se intensa crítica contra esses princípios. Numerosos autores, salientando-se Herbert Simon ${ }^{25}$ entre eles, negaram qualquer validade aos princípios clássicos de administração, porque eles vêm em pares opostos, tendendo a se anular mutuamente: "É um defeito fatal que os princípios de administração, como provérbios, ocorrem aos pares. Para quase qualquer princípio, pode-se encontrar outro igualmente plausível e contraditório. Embora os dois princípios do par nos levem a recomendações opostas, não há nada na teoria que indique qual é o que deve ser adotado. Por exemplo, nas costumeiras discussôes a respeito da centralização versus descentralização, concluise, em geral, que, de um lado, a centralização das tomadas de decisões é altamente desejável; do outro lado, há vantagens definidas na descentralização."

O considerável desenvolvimento dos estudos quantitativos verificado nos dois últimos decênios no campo da Adminis- 
tração constitui, em parte, um esforço de reconciliação dos princípios opostos. Vimos, numa série de exemplos apresentados neste artigo, como a criação de modelos permite estudar o efeito de pares de princípios, visando a encontrar o ponto de equilíbrio das tendências contraditórias. O progresso da Ciência da Administração restitui a legitimidade aos princípios clássicos e define com maior precisão o seu efeito. Nas palavras de Koontz e O'Donnel ${ }^{26}$, "nenhum executivo pode ser completamente a favor ou contra a centralização. As proposições devem ser sempre em termos de 'mais ou menos', em termos de 'quanto"....

Um físico, certamente, não diria que o princípio de gravitação é nulo meramente porque pode ser contrabalançado pelo princípio da força centrífuga..."

\section{CONCLUSÃO}

O administrador pretende, muitas vezes, resolver seus problemas propondo soluções baseadas num princípio. Por exemplo, evoca o princípio da descentralização para modificar a organização vigente; o de padronização, para reduzir a linha; ou ainda o de separação do controle, para justificar a criação de uma seção autônoma de inspeção. Entretanto, o estado atual dos conhecimentos administrativos já obriga o dirigente da empresa a qualificar melhor, isto é, a quantificar suas opiniões.

Estudamos nestas páginas um modelo quantitativo de grande aplicação para o administrador de produção, o modelo de custo mínimo. $O$ raciocínio que consiste em definir exatamente as alternativas e calcular os diversos custos, para cada alternativa, será sempre mais utilizado, tornando-se cada vez mais técnica a função do administrador profissional.

\section{COMENTÁRIOS DO AUTOR}

Desde a publicação deste artigo, substanciais mudanças ocorreram nos métodos de trabalho e procedimentos administrativos da área fabril. As assim chamadas "técnicas japonesas modernas" rejeitam as soluções de compromisso, como lote econômico de compras e produção, estoques de segurança, nível aceitável de qualidade e paradas toleráveis de equipamento. A tendência atual é a procura do absoluto: zero estoque, zero defeito, zero reclamações, zero tempo de ajuste e preparo de máquinas, zero parada, zero tempo de entrega, zero atraso, zero acidente e zero papel.

Em termos do modelo aqui apresentado, as empresas parecem ter optado por uma ponta, e não mais por um ponto intermediário. Entretanto, as circunstâncias que permitiram o deslocamento das curvas de custo e, em consequiência, a migração do ponto de otimização para um extremo, não se reproduzem sempre em todos os países, setores e empresas. Por exemplo, atingir o estoque zero é possível desde que o cliente disponha de poder para impor ao seu fornecedor de insumos a obrigação de efetuar entregas diárias, e que, ademais, as distâncias, a malha rodoviária, o trânsito e a legislação fiscal não se constituam em dispendiosos obstáculos. Qualidade superlativa é factível desde que a empresa e a sociedade tenham realizado consideráveis investimentos, a ser levados em conta na curva dos custos "inevitáveis" de qualidade, no treinamento e na conscientização dos empregados. Parada zero de equipamentos e ajuste rápido das máquinas pressupõem pesados dispêndios em dispositivos especiais, que constituem uma barreira instransponível para a maior parte de nossas empresas, ressalva feita à grandes montadoras. Um dos custos opostos a que o modelo em foco se refere tornouse, em suma, menos explícito, mais oculto, porém, continua existindo. Os pressupostos do modelo clássico aqui apresentado permanecem, portanto, válidos. $\square$
26. KOONTZ, Harold; O'DONNEL, Cyril. Princípios de Administração. São Paulo: Pioneira, 1962.

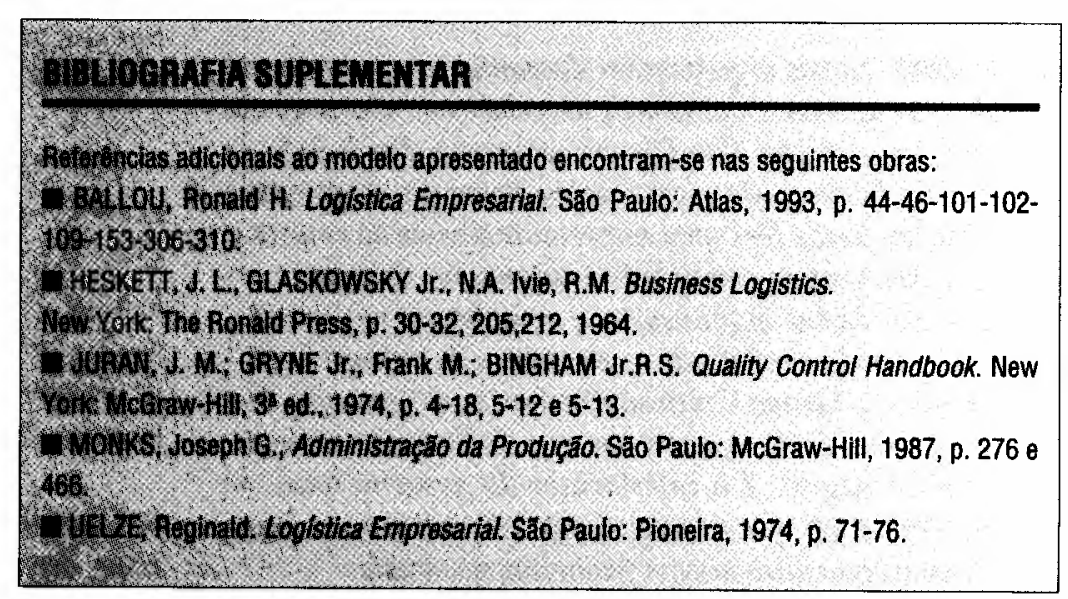

